Disponível em:

http://editora.unoesc.edu.br/index.php/race

Race, Joaçaba, v. 14, n. 3, p. 1269-1296, set./dez. 2015

\title{
SOLUÇÕES INSTANTÂNEAS E PADRONIZADAS UTILIZANDO A GESTÃO DO CONHECIMENTO: UMA ABORDAGEM QUANTO ÀS FORMAS DE DEMISSÃO
}

\section{Instant and Standardized Solutions using Knowledge Management: an approach on forms of dismissal}

Cleber Augusto Pereira

E-mail:kcleber@gmail.com

Mestre em Engenharia Elétrica pela

Universidade Federal do Maranhão; doutorando em Ciências da Administração pela Universidade do Minho; Professor assistente da Universidade Federal do Maranhão.

Endereço para contato: Avenida dos Portugueses, 1966, Bacanga, 65080-805, São Luís, Maranhão, Brasil.

Neimar Sousa Pinto Pereira

E-mail: neimar.anjo@gmail.com

Mestre em Administração e Controladoria pela Universidade Federal do Ceará; doutoranda em Ciências Empresariais pela Universidade do Minho; Professora assistente da Universidade Federal do Maranhão.

Renato Pereira Monteiro

E-mail: renato.monteiro@poa.ifrs.edu.br

Mestre em Ciências Contábeis pela Universidade do Vale do Rio dos Sinos; doutorando em Contabilidade pelas Universidades do Minho e Aveiro; Diretor de Administração e Planejamento do Instituto Federal de Educação, Ciência e Tecnologia do Rio Grande do Sul; Professor da Universidade do Minho.

Artigo recebido em 05 de novembro de 2014. Aceito em 03 de agosto de 2015. 


\section{Resumo}

O objetivo principal com este estudo foi realizar uma discussão crítica dos aspectos relativos à aplicação de soluções instantâneas e de forma padronizada na empresa para a solução de conflitos organizacionais. Para tal, a estratégia adotada foi realizar uma interpretação do contexto de relações organizacionais retratadas no filme $U p$ in the air. Para essa interpretação, fundamentalmente, utilizaram-se conceitos da teoria organizacional. Foram escolhidas três principais dimensões de análise: formas convencionais, contraditórias e os diferentes contextos de demissão. Essas formas permitiram a realização da abordagem ao filme, e, sob esse prisma, foi realizada a discussão, construído o mapa conceitual e o modelo conceitual da pesquisa e, posteriormente, discutidos os achados, sempre se procurando identificar a relação entre estes e a teoria organizacional. Utilizou-se neste estudo a revisão sistemática de literatura, escolhida depois de assistido o filme e a partir da reflexão sobre as anotações da síntese. Realizou-se, ainda, a combinação do modelo de análise de filmes proposto por Denzin e Lincoln (2005), que permitiu elaborar uma lista de dimensões ou habilidades possíveis de serem discutidas e posterior associação com a seleção dos artigos em periódicos de fator de impacto relevante, o que culminou na construção do modelo conceitual do trabalho. Além disso, foi utilizada uma metodologia para a apresentação visual dos conceitos-chave por meio de um diagrama hierárquico, o mapa conceitual, que permitiu o melhor entendimento das principais palavras/ conceitos-chave. Os principais resultados do estudo estão vinculados à discussão da aplicação dos conceitos extraídos do filme sob a ótica da teoria organizacional e promovem a reflexão entre o observado no filme e as formas de se evitar o caos organizacional.

Palavras-chave: Demissão. Formas tradicionais. Formas contraditórias. Soluções padronizadas.

\section{Instant and Standardized Solutions using Knowledge Management: an approach on forms to dismissal}

Abstract

The main objective with this study was to conduct a critical discussion of the issues related to the implementation of instant solutions and in a standardized way in a company in order to solve organizational conflicts. In doing so, the strategy adopted was an interpretation of the context of organizational relationships shown in the film "Up in the air". For this interpretation, we have primarily used concepts of organizational theory and chosen three main dimensions of analysis: conventional, contradictory forms and several contexts of dismissal. These forms allowed to make an approach to the film and on this, the discussion took place, building up the concept map and the conceptual research model and, further, the findings were discussed, always seeking to identify the relation between these and the organizational theory. In this study it has been used a systematic review of literature, chosen after watching the film and by reflecting upon the notes from the synthesis. The combination of the model of film analysis proposed by Denzin and Lincoln (2005) took place, which allowed to establish a list of dimensions or skills possible to be discussed and later association with the selection of articles in journals eith relevant impact factor, whats culminated in the construction of the conceptual model of work. Besides, it was used a methodology for visual presentation of the key concepts 
through a hierarchical diagram, concept map, which allowed a better understanding of the keywords/key concepts. The main results of the study are bond to the discussion of application of the concepts elicited from the film under the point of view of the organizational theory and promote the reflection between the observed in the film and the ways of avoiding organizational chaos.

Keywords: Dismissal. Traditional ways. Contradictory ways. Standardized solutions.

\section{INTRODUÇÃO}

O presente trabalho é apresentado na forma de ensaio crítico, sendo realizada uma abordagem aplicada ao filme $U p$ on the air, com base nas diferentes formas de demissão e na teoria organizacional. O objetivo principal com este estudo é realizar uma discussão crítica dos aspectos relativos à aplicação de soluções instantâneas e de forma padronizada na empresa para a solução de conflitos organizacionais. Entendase como soluções instantâneas a aplicação de tecnologia como forma de automatizar o processo de demissão, utilizando-se softwares aplicados a essa finalidade, com o principal objetivo de otimizar o processo e reduzir custos associados à atividade, principalmente em grandes corporações com diversas filiais, como despesas com viagens dos agentes que realizam essas tarefas na empresa de outplacement.

Morin e Yorks (1990, p. 157) apresentam uma definição de outplacement que pode ser aplicada a esse contexto: “Treinamento e suporte sistemático dado para pessoas demitidas, onde o propósito é proporcionar conselho, instruções e técnicas para auxiliar o profissional a organizar e realizar um programa de busca de uma nova colocação.”

A proposta do filme de aplicar padrões previamente estabelecidos para a automatização do processo demissional, na forma de checklist, combina de forma sinérgica com as ferramentas tecnológicas, porém, destoa da realidade contemporânea do processo de demissão. Na busca por resultados organizacionais, a tendência de aplicação de soluções generalistas no escopo da organização necessita ser pensada, pois a utilização de padrões pode resolver a maioria dos problemas conhecidos, mas pode ignorar outros aspectos ainda não considerados e novos problemas.

Justifica-se este estudo, que busca discutir as formas tradicionais e contraditórias de demissão identificadas na literatura, tomando como referência as premissas da legislação trabalhista de diferentes países e pesquisando maneiras inovadoras em teste nas organizações. A discussão dos diferentes contextos organizacionais é contrastante com as pressões ambientais por resultados. Suas 
implicações éticas e comportamentais são mais evidentes quando o processo é conduzido por uma empresa terceirizada, como se identifica no filme.

O protocolo para a realização da revisão sistemática de literatura foi elaborado após assistido o filme e a partir da reflexão sobre as anotações da síntese, formulou-se uma lista de dimensões ou habilidades possíveis de serem discutidas, e passou-se, então, à seleção dos artigos em periódicos de fator de impacto (FI) relevante. Entenda-se como FI relevante, nesse contexto, periódicos indexados na base de dados da Scopus com FI >=1 e preferencialmente já citados.

Esta primeira seção apresenta uma síntese do ensaio e os principais objetivos. A segunda seção apresenta as metodologias utilizadas no trabalho: para a revisão sistemática de literatura, a representação visual dos conceitos e de análise do filme. $\mathrm{Na}$ terceira seção é apresentada a revisão de literatura e o modelo conceitual proposto no trabalho. Na quarta seção se realiza a discussão dos aspectos identificados no filme Up in the air com base na discussão teórica e na teoria organizacional. A apresentação das conclusões e contribuições deste ensaio são apresentadas na última seção.

\section{METODOLOGIA}

Nesta seção apresentam-se as metodologias utilizadas para a revisão sistemática de literatura, a representação visual dos conceitos oriundos do referencial teórico e a forma de análise aplicada aos achados do filme.

\subsection{METODOLOGIA DE ANÁLISE DO FILME}

Para o enquadramento teórico deste trabalho, por se tratar de análise dependente de fragmentos extraídos do filme, primeiramente foi assistido ao filme Up in the air para análise do contexto geral apresentado e ambientação. Como os filmes podem ser interpretados e analisados de inúmeras perspectivas, gerou-se, em seguida, uma síntese do filme contendo os agentes e as principais discussões, para extração dos conceitos associados à teoria organizacional.

Foi utilizada uma adaptação do modelo de análise de filmes como instrumento de investigação (DENZIN; LINCOLN, 2005, p. 231-232), seguindose as etapas para o modelo geral de análise de filme: o filme foi analisado como um todo, realizando-se o registro das impressões, questionamentos e significados 
importantes associados à proposta de análise; foram formuladas as questões de investigação a serem exploradas na forma de dimensões e habilidades e anotando-se as principais características das cenas-chave; e foi considerada a leitura do ponto de vista realista e subversivo do filme para escrever a interpretação final.

A partir da reflexão sobre as anotações da síntese, foi elaborada uma lista de dimensões ou habilidades dos fatores críticos associados ao processo de demissão e à tarefa de demitir, passíveis de serem discutidas com base no filme. Passou-se, então, à determinação das palavras-chave, em língua inglesa, para cada dimensão predeterminada.

Os critérios adotados para essa escolha se basearam na associação entre as possíveis abordagens ao filme, ao mapeamento dos conceitos e às relações organizacionais definidas no mapa conceitual e a análise das ênfases destacadas no modelo conceitual do estudo.

São apresentados, no Esquema 1, os critérios adotados para a definição e seleção das palavras-chave. Essa escolha permitiu subsidiar o protocolo de pesquisa a ser utilizado na revisão sistemática de literatura.

Esquema 1 - Critérios adotados para definição das palavras-chave

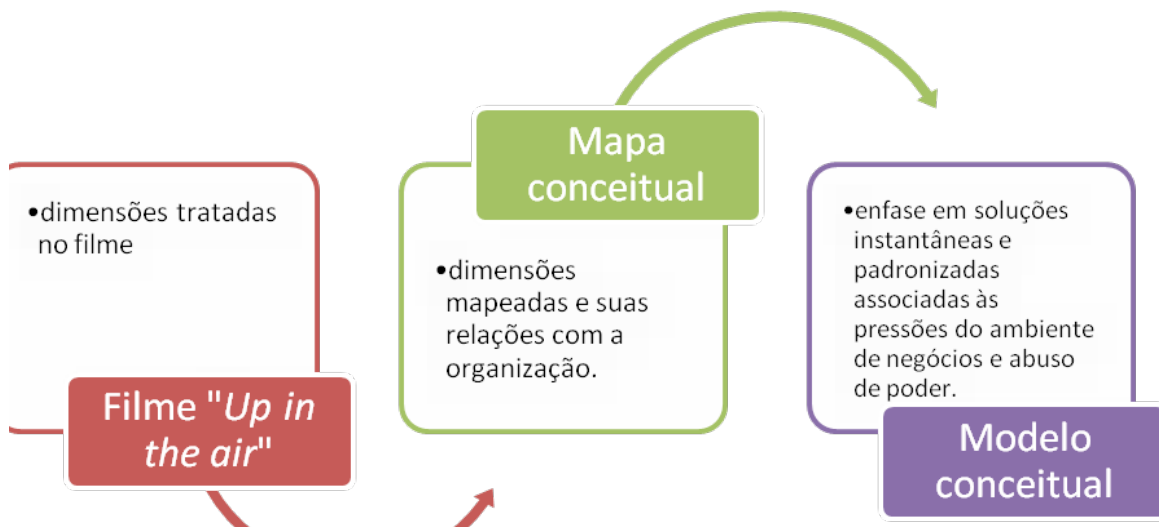

Fonte: os autores.

As palavras-chave definidas na filtragem foram dismiss, organizational theory, dismiss law, outplacement, occupational contexts, ethical approach e job termination. A próxima seção explica como foram utilizadas as palavras-chave para o delineamento da revisão sistemática de literatura. 


\subsection{METODOLOGIA DE REVISÃO SISTEMÁTICA DE LITERATURA}

A metodologia utilizada para a revisão sistemática de literatura foi pensada após se assistir ao filme e a partir da lista de dimensões ou habilidades possíveis de serem discutidas, apresentadas na seção anterior. Passou-se, então, à seleção dos artigos em periódicos de renome e fator de impacto relevante, o que culminou na construção do mapa conceitual e do modelo conceitual do trabalho.

Após a definição das palavras-chave, passou-se à etapa de busca em base de dados referencial e multidisciplinar. Foi selecionada uma fonte de pesquisa referencial de reconhecida excelência na academia: a base de dados da Scopus, disponibilizada pela editora Elsevier, que é uma base de dados de referência bibliográfica multidisciplinar, que indexa, aproximadamente, 19.500 revistas com arbitragem científica, de mais de 5.000 editoras internacionais.

Para o melhor planejamento da busca, foi utilizado um protocolo de pesquisa (ver Apêndice B - Protocolo de Pesquisa) para auxílio na definição antes de a pesquisa ocorrer, no sentido de permitir o pensar nos critérios de seleção das fontes de informação e garantir que a seleção ocorra de acordo com aquilo que se pretende. $\mathrm{O}$ protocolo de pesquisa baseia-se em uma adaptação de métodos de revisão de literatura para aplicação nas áreas de ciências sociais (TRANFIELD; MOUCHEL, 2002; TRANFIELD; DENYER; SMART, 2003; SAUR-AMARAL, 2011). O protocolo de pesquisa detalhado, com os procedimentos e critérios de pesquisa, consta no Apêndice B.

Os resultados da filtragem constante no Apêndice B foram exportados para um gerenciador de referências e formam uma base referencial panorâmica do que vem sendo discutido na área deste trabalho.

Após realizada a revisão sistemática dos abstracts e com base nos estudos empíricos selecionados, foram anexados os artigos completos em formato digital e criado um esboço teórico de congruência das dimensões e habilidades entre os trabalhos, com suas principais características e resultados. Com base nas referências selecionadas, pôde ser elaborada a revisão de literatura deste estudo.

A próxima seção explica o método utilizado para a apresentação visual dos conceitos descobertos durante a análise, o mapa conceitual. 


\subsection{METODOLOGIA DE APRESENTAÇÃO VISUAL UTILIZANDO DIAGRAMA HIERÁRQUICO - MAPA CONCEITUAL}

Com base nos achados da revisão de literatura citada na seção anterior e após a delimitação do esboço teórico e análise das dimensões discutidas nos trabalhos selecionados, foi possível elaborar as relações entre os conceitos.

O software computacional utilizado para a elaboração do mapa conceitual foi o Cmap Tools Knowledge Modelling Kit, uma ferramenta metodológica que utiliza a teoria de assimilação para determinar o que o estudante sabe ou descobriu durante a revisão de literatura (CAÑAS et al., 2000, p. 1-2). Em um recente estudo (HAGEMANS; VAN DER MEIJ; DE JONG, 2013), relata-se a experiência positiva de estudantes que visualizaram o mapa conceitual e superaram os estudantes que realizaram apenas a análise descritiva. Os resultados mostraram que a utilização de mapas conceituais contribui com a melhoria da aprendizagem e a descoberta de relações entre conceitos.

A maneira escolhida para representar visualmente, na forma de proposições, as relações significativas entre os conceitos foi a utilização de um diagrama hierárquico, o mapa conceitual, muito utilizado nos estudos de gestão do conhecimento. O mapa conceitual pode ser entendido como um diagrama bidimensional que tem como principal função demonstrar conceitos hierarquicamente organizados e as relações entre conceitos. As linhas de conexão representam as relações entre conceitos (MOON et al., 2011).

Dessa forma, pelas contribuições da utilização de mapas conceituais anteriormente descritas, justifica-se a aplicação de mapa conceitual para demonstrar os conceitos e relacionamentos aplicados na forma de palavras-chave na busca de delimitação teórica para a análise. As palavras-chave, que representam os principais conceitos identificados na relação entre filme e literatura, e suas relações com as habilidades esperadas em cada dimensão analisada, são representadas em um diagrama bidimensional, o mapa conceitual, constante no Esquema 2. 
Esquema 2 - Mapa Conceitual das relações e conceitos expressados por meio das palavras-chave

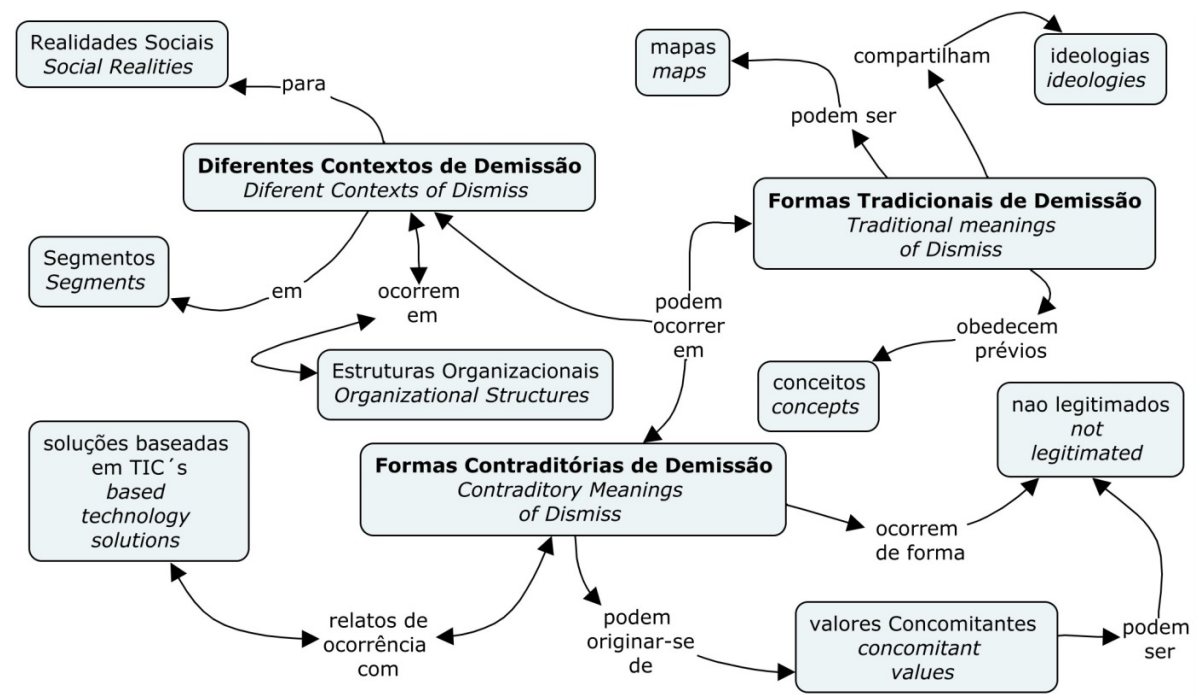

Fonte: os autores.

\subsubsection{LEITURA DO DIAGRAMA HIERÁRQUICO - MAPA CONCEITUAL}

No mapa conceitual, mostrado no Esquema 2, podem ser identificados, em negrito, os principais conceitos que são discutidos nesta abordagem aplicada ao filme: formas tradicionais de demissão, formas contraditórias de demissão, e diferentes contextos.

Ressalte-se que fica visualmente evidente que tanto as formas tradicionais quanto as formas contraditórias de demissão são passíveis de ocorrer nos diferentes contextos e áreas das distintas organizações.

Mais especificamente na compreensão da relação entre os conceitos, o mapa permite identificar que, na abordagem do filme em questão, a aplicação de soluções baseadas em tecnologia (soluções padronizadas), além de poder ocorrer a partir de valores distintos e concomitantes existentes dentro da mesma organização, estas podem não ser legitimadas pelos seus colaboradores, o que representa o caso específico do filme, tendendo a gerar conflito e caos nas organizações. Essa abordagem permite identificar que os principais problemas identificados no estudo se relacionam essa dimensão, formas contraditórias de demissão, e ensejam a pesquisa na literatura de como isso vem ocorrendo nas organizações. 
Delineadas as metodologias aplicadas neste estudo, a próxima seção apresenta e discute o referencial teórico e o modelo conceitual aplicados neste trabalho.

\section{REVISÃO DE LITERATURA}

Para a revisão de literatura aplicada a este trabalho, considerou-se, inicialmente, a necessidade de assistir ao filme Up on the air (2009) e realizar a análise e a demarcação de possíveis eixos temáticos a serem desenvolvidos neste ensaio.

Após a reflexão quanto ao tipo de abordagem, convencionou-se que a linha de discussão a ser realizada versaria sobre as relações de abuso de poder; do ponto de vista das organizações, essa discussão é pertinente, pois a empresa como o personagem principal se caracteriza como uma outplacement, atuando como terceirizada especializada nos trabalhos de demissão de funcionários. A abordagem considera ainda a questão de implantação de solução computacional instantânea e padronizada no sentido de substituir/evoluir o tipo de trabalho até então desenvolvido por esses funcionários, tomando como base o objetivo institucional de redução de custos com passagens aéreas, estadias e diárias próximas à ordem de $85 \%$ dos custos atuais.

Quanto às questões de dispensa e demissão, inúmeras abordagens evidenciam as políticas, os acontecimentos e as melhores práticas em uso em diversificadas empresas e segmentos (EBY; BUCH, 1998; GOODMAN et al., 1998; PILAR; MIGUEL, 2007; SOUTHEY, 2008; KELLNER; MCDONALD; WATERHOUSE, 2011; FREYENS; OSLINGTON, 2013).

Ainda, é importante refletir quanto às políticas organizacionais e suas implicações e adequações nas empresas em relação à legislação atual (STIEBER; BLOCK; KRUEGER, 1992; CARBY-HALL, 2001; GRUND, 2006; PILAR; MIGUEL, 2007; SOUTHEY, 2008; KELLNER; MCDONALD; WATERHOUSE, 2011), considerando-se os trabalhos que permitem a reflexão dessas políticas e o atendimento das exigências legais em vigor.

O modelo conceitual proposto para esta revisão de literatura é demonstrado no Esquema 3 e considera três principais dimensões: maneiras tradicionais de desempenho de atividades (traditional meanings), maneiras contraditórias (contraditory meanings) e discussão dos diferentes contextos (diferent contexts), pois, no caso de empresa terceirizada, a prestação de serviços inevitavelmente ocorrerá em empresas e cenários distintos. 
Esquema 3 - Modelo conceitual da revisão sistemática de literatura

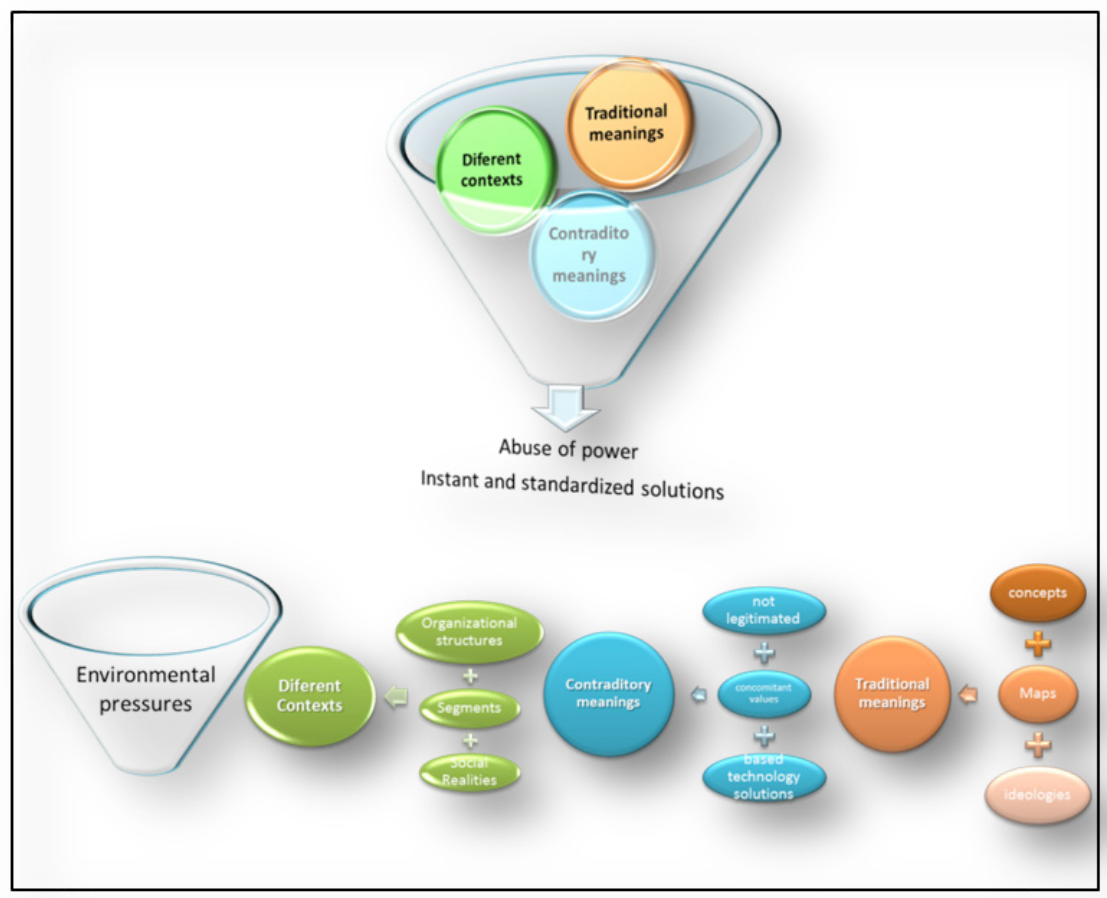

Fonte: os autores.

Inerente a todo o contexto, é importante considerar o cenário organizacional moderno no qual, em busca de vantagem competitiva, acaba-se por estabelecer consequentes metas de redução de custos, gerando pressões no ambiente interno da organização normalmente ocasionadas pela competição do mercado externo.

As próximas seções apresentam as três dimensões analisadas no filme: formas tradicionais de demissão, discussão dos diferentes contextos e formas contraditórias de demissão.

\subsection{FORMAS TRADICIONAIS DE DEMISSÃO}

Os processos de dispensa de pessoal que utilizam meios tradicionais devem ser entendidos em formas de conceitos que mapeiam os valores funcionais e formam as ideologias organizacionais. O processo está descrito na próxima seção. 


\subsubsection{Relação entre Conceitos, Mapas e Ideologia}

Esses conceitos derivam de formas de resolver processos similares e experiências anteriores. Para entender os relacionamentos entre estes, devem estar no mesmo contexto para serem validados. A necessidade de mapear esses conceitos emerge para permitir o relacionamento entre eles, como forma subjetiva de explanar suas associações e entender as maneiras aplicadas ao contexto. As estruturas são as formas utilizadas (mapeamento dos conceitos) para representar os valores implícitos e funcionais que, encadeados logicamente, dão forma às ideologias (GRAY; BOUGON; DONNELLON, 1985).

Essas definições são importantes dimensões que ocorrem dentro do ambiente organizacional e são implícitas ao desenvolvimento de atividades na organização, podem influenciar positiva ou negativamente nas formas de trabalho e de demissão de funcionários, compondo a cultura da organização.

Notou-se no filme que a rápida intenção de alteração de valores organizacionais sem pensar e avaliar seus impactos gerou um clima instável na organização e foi refletido na frente de atuação, ou seja, na alteração comportamental dos profissionais demitidos. A próxima seção passa a discutir as formas tradicionais e esperadas de demissão apresentadas na literatura.

\subsubsection{As formas tradicionais de demissão encontradas na literatura}

Iniciando esta discussão, o trabalho de Pilar e Miguel (2007) utilizou dados da Espanha no período de 1987 a 2001 e apresenta a influência jurídica, avaliando como esta afeta a relação entre as condições do mercado de trabalho e as demissões. Entre os achados, verificou-se que as reformas de Direito do Trabalho exerceram efeitos sobre o uso de desligamentos individuais e coletivos. Identificou-se nos resultados uma estratégica utilização de diferentes tipos de demissão por parte das empresas, distorcendo o trabalho das instituições envolvidas em demissões.

Em um estudo na Austrália, mais recente e mais compactado, Freyens e Oslington (2013) debatem sobre a regulamentação de demissões que estava intensa nos últimos anos e que foi renovada em período anterior a 2012 com revisão da Lei Work Fair. O trabalho revisa as alterações legislativas da Lei das Relações de Trabalho que funcionaram entre 1993 e 2006, as alterações de 2006 a 2009 e as da Lei Work Fair a partir de 2009 e compara os padrões de apresentação e os resultados com base 
nos dados fornecidos pela Work Fair na Austrália sobre o funcionamento do sistema de despedimento sem justa causa, conforme previsto na lei. Os achados reforçam que os custos impostos às empresas e ao emprego são modestos, mas tornam-se necessários mais postos de trabalho de regulação na demissão.

Ainda na Austrália, o artigo de Kellner, Mcdonald e Waterhouse (2011) aborda o momento em que o relacionamento de trabalho termina para os jovens. Ele examina a frequência das diferentes formas de demissão e as circunstâncias que precederam as demissões por meio de uma análise de conteúdo de 1.259 casos de inquéritos empregados em uma organização. Os resultados indicaram que a demissão foi mais comumente associada com bullying, assédio e pedido pessoal. Os jovens relataram alegações de má conduta como precedente na demissão, enquanto as mulheres apresentaram taxas mais elevadas de assédio sexual e discriminação. A pesquisa destaca os tipos e as circunstâncias da demissão por meio de uma variedade de contextos de trabalho e revela as complexidades das relações de emprego de jovens que podem ser diferentes da força de trabalho em geral.

Ocorrendo durante um processo de reestruturação empresarial, em seu trabalho, Eby e Buch (1998) discutem o tratamento de empregados durante downsizing e reestruturação societária, o qual levantou muitas questões éticas. A compreensão de decisões éticas organizacionais, ao entregar a notícia da demissão aos funcionários afetados, utilizou a Teoria do Contrato Social. Foi considerada de particular importância a determinação dos três critérios utilizados para gerenciar o processo de demissão dentro de limites éticos: aviso prévio da perda de emprego, comunicação aberta e serviços de apoio institucionalizados.

A próxima seção aborda a questão dos diferentes contextos organizacionais em que áreas de atuação e visões diferentes influenciam diretamente o cenário da organização.

\subsection{DIFERENTES CONTEXTOS}

Os diferentes contextos devem ser entendidos como produto da diversidade das estruturas organizacionais, dos diferentes segmentos de atuação das organizações e da diversidade de realidade social inevitável dentro de um conglomerado de pessoas (ver descrição no Esquema 3).

Considerando os mais diferentes contextos organizacionais e sabendo-se que o processo de demissão é inerente à prática organizacional, o trabalho de Carby- 
Hall (2001) expõe uma rota alternativa para demissões utilizando a arbitragem voluntária como uma alternativa a uma audiência em tribunais de trabalho, a qual fornece uma escolha às partes em disputa para ter a reivindicação ouvida em um tribunal de trabalho ou por um árbitro nomeado. Essa nova alternativa de arbitragem, embora lenta, pode vir a tornar-se aceitável, apesar de suas desvantagens, por buscar um caminho mais justo a oferecer, independente da parte.

As áreas de hotéis e catering, transporte rodoviário e engenharia, historicamente, refletem diferentes formas de demissão e são comuns casos de despedimento ilícito. Nesse contexto, Goodman et al.(1998) realizam um estudo de caso nesses três setores no Reino Unido. A pesquisa está estruturada em comparações pareadas de pequenas empresas e analisou os procedimentos disciplinares nestas, além das práticas de recrutamento e estilo e métodos de gestão. Uma das descobertas mais surpreendentes do trabalho foi a falta de oposição da gestão à introdução de procedimentos escritos formais. De modo geral, os gestores não contestaram a conveniência de regras e procedimentos escritos, mas, muitas vezes, apontaram para os benefícios positivos que poderiam fluir a partir deles.

Em recente publicação, Haran (2013) discute as diferentes visões de descontinuidade de contrato entre pessoa e organização na percepção de que as corporações podem quebrar contratos, mas os indivíduos não podem. Enquanto os contratos são tipicamente vistos como promessas moralmente vinculantes ou instrumentos de negócios moralmente neutros, a análise mostra que os contratos de indivíduos estão associados mais fortemente com promessas do que com contratos de organizações. Como resultado, a quebra de contrato por um indivíduo é vista como uma transgressão moral. $\mathrm{O}$ mesmo comportamento por uma organização, no entanto, é visto mais como uma decisão de negócio legítimo.

A desconexão entre as teorias de gestão e as aplicações da vida real novamente não conseguem explicar, na prática das organizações, como ocorre a gestão responsável com políticas e sistemas de incentivo à produtividade. Hilliard (2013) reforça que parte disso ocorre em razão da complexidade e da natureza holística do campo e em decorrência do fato de que muitos dos benefícios de alinhar os objetivos de negócios com a mudança de condições sociais são de natureza intangível. Em seu trabalho, com base no modelo Desempenho Social Corporativo, o autor analisa a questão do ponto de vista das responsabilidades, a capacidade de resposta e os resultados, considerando o efeito custo - benefício de incorporar a variável responsabilidade social na estrutura salarial para medir o impacto sobre a produtividade. 
Discutiu-se abertamente a estabilidade no emprego como um fator benéfico e ao mesmo tempo dificultador do desempenho no trabalho sob o prisma de entediamento e falta de motivação. Ao mesmo tempo se exploraram de forma intrapessoal os impactos do envelhecimento no trabalho também comparando a sua relação com o desempenho. Os achados deste estudo contrapõem as expectativas do ponto de vista dos funcionários quando expõem serem observadas grandes mudanças relacionadas ao envelhecimento alterando capacidade cognitiva, personalidade, orientação para a meta, a experiência social e emocional, e saúde do trabalhador (NG; FELDMAN, 2013a, 2013b).

\subsection{FORMAS CONTRADITÓRIAS}

As maneiras contraditórias aqui apresentadas deverão ser entendidas como maneiras não necessariamente legitimadas tanto em lei quanto institucionalmente. Podendo, ainda, em diferentes empresas, ser identificados valores concomitantes em utilização de forma simultânea. Na tentativa de reduzir custos e agilizar os processos, verifica-se no cenário empresarial a adoção de soluções ou sistemas computacionais baseados em tecnologia. Estas têm recebido especial atenção como forma de padronizar procedimentos e reações organizacionais, engessando a subjetividade das relações sociais e alienando as relações individuais, como retratado no filme (ver descrição no Esquema 3).

Entre as inúmeras maneiras de obter sucesso no mercado, as empresas têm buscado maneiras não convencionais e, em algumas vezes, formas contraditórias de obter vantagens competitivas. Por exemplo, em estudo realizado com 160 empresas de tecnologia da Europa (MARTIN-ROJAS; GARCIA-MORALES; BOLIVAR-RAMOS, 2013) demonstra a influência do apoio tecnológico e do empreendedorismo corporativo em empresas da área. As diferentes variáveis tecnológicas estão diretamente ligadas ao nível de capacitação tecnológica e competências distintas, podendo influenciar positivamente ou negativamente no desempenho organizacional.

No caso da aplicação de uma solução de TI apresentada no filme Up in the air, pode-se ressaltar que a tentativa de implantação de ferramentas computacionais, para exercer as atividades de demissão de funcionários, demonstrou-se incapaz de alcançar os mesmos resultados de um encontro pessoal e formal - método tradicional. 
Finalmente, uma empresa de outplacement como a abordada no filme tem sido utilizada pelas empresas contratantes como um mecanismo de escape da responsabilidade de feedback e desligamento com critérios, que levam ao julgamento preliminar de falta de postura ética por parte das organizações. Nesse sentido, o trabalho de Miller e Robinson (2004) avaliou o gerenciamento da decepção de rescisão de contrato de trabalho por intermédio de empresas de outplacement como um dispositivo utilizado para amenizar o fato demissional, tornando-se comum entre os trabalhadores de alto escalão que a própria empresa que o dispensa se proponha a contribuir para a sua reinserção profissional. Os defensores de outplacement têm enfatizado aos empregadores que esses serviços funcionam principalmente como um dispositivo de autoproteção, minimizando as reações problemáticas das pessoas que perderam o emprego e de transeuntes. Notou-se no filme que as reações continuam a existir, porém, após determinado período de tempo que a pessoa leva para assimilar a ideia, o tratamento de reinserção profissional realizado por empresa alheia pode impactar positivamente nessas pessoas.

Do ponto de vista de aplicação de tecnologia, Kuettner, Diehl e Schubert (2013) apresentam resultados contraditórios, mudanças e desafios quando comparam fatores com iniciativas de implantação de solução computacional, como o Enterprise Resource Plaining (ERP). O trabalho discute e contrasta resultados, semelhanças e distinções entre Enterprise 2.0 e projetos de ERP. Os resultados indicam que iniciativas Enterprise 2.0 envolvem fatores de mudanças específicas, requerem estratégias de gestão distintas e forma novos papéis na organização. Para os pesquisadores, o estudo constitui um ponto de partida para examinar empiricamente a mudança nas iniciativas da Enterprise 2.0.

\section{DA ABORDAGEM TEÓRICA ÀS OBSERVAÇÕES IDENTIFICADAS NO FILME UP IN THE AIR}

Nesta seção, tem-se o objetivo de consolidar as observações do filme Up in the air com base no referencial teórico explicitado por meio do modelo conceitual deste trabalho. Como se trata de análise de um filme, tornou-se necessário definir a abordagem a ser realizada com base apenas nos aspectos fundamentais para esse fim. Portanto, as discussões a serem colocadas em pauta considerarão apenas os fatos necessários e importantes da temática proposta. 
Para isso, primeiro, considerando-se que a empresa na qual o personagem principal trabalha é uma outplacement, alinhada à definição de Morin e Yorks (1990) e atuando na dispensa de funcionários de empresas das mais diversas áreas, a abordagem inicial fará uma explanação das formas de executar o trabalho e das características desses profissionais.

Segundo, ao considerar a chegada de Natalie Keener na empresa com a proposta de demissões virtuais, essa abordagem toma a notação de utilização de formas contraditórias e não homologadas de tratar o processo de desligamento de colaboradores e merece seu espaço. Essa opção de utilização de formas virtuais foi estudada por Kuettner, Diehl e Schubert (2013), os quais afirmam que essas opções devem ainda ser sustentadas por sistema informático e envolvem fatores de mudanças específicas.

Terceiro, notou-se que em cada empresa em que "voavam" para "atender" existia uma agenda específica e um cenário anterior não necessariamente contextualizado no filme, mas que deixava as "aspas" de que, em algumas situações, os funcionários previam que a dispensa estava por vir. Isso vai ao encontro do tratado por Haran (2013) quando identifica que as corporações podem quebrar contratos, mas os indivíduos não, pois seria entendido como falta de ética dos funcionários. Já esse tipo de quebra é aceito no meio como normal ou, como destacado pelo referido autor, uma decisão de negócio legítimo.

Colocando-se essas três variáveis como contexto da abordagem ao filme, o "funil" que condensa estas variáveis acrescenta as pressões ambientais, tanto internas: o desenvolvimento e os testes da nova forma contraditória de dispensa utilizando videoconferência, quanto externas: as empresas em que as demissões deveriam ocorrer, com suas histórias e tensões.

Como produto dessa relação, pode-se verificar situações que anteriormente já eram difíceis de gerenciar, como, por exemplo, o questionamento de um funcionário do tipo: "Quem é você que chega aqui e vem me demitir?", as quais, a partir do novo contexto, passariam a ser mais difíceis de lidar por meio de uma conversa virtual. Com questões desse tipo e a nova forma de dispensar os funcionários, passam a emergir situações claras de abuso de poder e conflitos difíceis de serem resolvidos ao primeiro momento. 


\subsection{FORMAS CONVENCIONAIS, CONTRADITÓRIAS E OS DIFERENTES CONTEXTOS: A ABORDAGEM AO FILME}

"Quem construiu impérios e mudou o mundo passou por isso. E por ter passado por isso obteve sucesso. Essa é a verdade. Crie uma nova rotina e logo estará de pé de novo." (Ryan Binghan, interpretado por George Clooney) (UP IN THE AIR, 2009).

O filme tem como foco principal a vida profissional e alguns acontecimentos pessoais de Ryan Binghan, interpretado por George Clooney. O personagem é um exímio profissional de uma empresa que presta serviços de demissão e recolocação profissional de forma terceirizada a inúmeras empresas, em um contexto de crise nos Estados Unidos da América (EUA), o qual é considerado benéfico às atividades dessa empresa.

O tipo de trabalho executado por Ryan consiste em regulares e constantes viagens pelos EUA demitindo pessoas de seus respectivos trabalhos. Acredita-se que essa estratégia acaba por eximir parte da responsabilidade dos chefes e esconder fatos como falta de coragem ou até mesmo preparo para efetuar a demissão. Para o desempenho dessa atividade, Ryan tem a obrigação de conhecer muito bem a legislação em vigor, como destacado por Pilar e Miguel (2007) quando estudaram o caso da Espanha e identificaram a existência de forte influência jurídica nas condições do mercado de trabalho e também nas demissões. A legislação, mundialmente, vem sofrendo alterações no decorrer do tempo, como já foi discutido na revisão de literatura. Isso evidencia uma série de cuidados que devem ser adotados, além de afastar a vida pessoal da vida profissional. Esse perfil de Ryan é claramente evidenciado quando o filme relata as inúmeras palestras por ele ministradas em que sua abordagem "da mochila" prega o desapego com o "conteúdo da mochila" e com o "peso de cada mochila", figuras de linguagem que refletem ao fundo algumas características próprias.

Para Ryan, como está sempre em frequentes viagens, os hotéis e aeroportos tornaram-se seu ambiente, no qual ele mostra estar plenamente ambientado e preparado para a ação, de forma a não perder tempo. O filme relata que Ryan chega a passar, em média, somente 43 dias por ano em sua própria casa e os demais, viajando.

Em determinada cena do filme, com a chegada de Natalie na organização, Ryan passa a ter a responsabilidade de acompanhá-la em um projeto novo, considerando que a sua rotina de vida passaria a estar ameaçada com o projeto de 
diminuição de custos com viagens dos agentes e com a implementação de um novo sistema de demissões via videoconferência, tendência já estudada por Kuettner, Diehl e Schubert (2013) na revisão de literatura. "Esta Companhia mantém 23 pessoas viajando 250 dias por ano. É caro e ineficaz. Quando mostrei isso ao Craig, há 3 meses, ele disse que só é um problema se houver solução." (Natalie Keener, interpretada por Anna Kendrick) (UP IN THE AIR, 2009).

Uma das narrativas utilizada por Ryan para contrapor as mudanças propostas é o tratamento que as pessoas passariam a receber a partir da implantação daquele sistema. De certa forma, ele possuía um know-how no que fazia e passou a imagem de que o seu trabalho não poderia ser reproduzido por uma câmera. Essa constatação de Ryan pode ser associada à realidade empresarial evidenciada no estudo de Kellner, Mcdonald e Waterhouse (2011). Os autores identificaram que as demissões ocorrem em diferentes contextos e circunstâncias e que as motivações variam de acordo com gênero, faixa etária, entre inúmeros outros fatores, enfim, quando se trata de demissão, cada caso deve ter uma abordagem específica. Esses aspectos, percebidos e tratados da forma correta e com a devida atenção por parte da empresa, podem servir como medidas corretivas e colaborar para a minimização de problemas de indenizações e processos trabalhistas futuros.

A proposta de Natalie Keener (UP IN THE AIR, 2009) de estabelecer uma rotina da demissão on-line por videoconferência propõe reduzir em $85 \%$ os custos da empresa. Porém, nota-se uma atitude fria e mecanizada no processo de comunicação da demissão. $O$ trecho citado a seguir reproduz suas palavras a um colaborador durante o processo de demissão via videoconferência: "Analise o manual à sua frente. As respostas que procura estão aí. [...] Antes que perceba, estará a caminho de novas oportunidades. [...]Pânico não ajuda a ninguém. (UP IN THE AIR, 2009).

Como Ryan estava prestando um tipo de mentoring à Natalie, esta passa a acompanhá-lo em seu labor e começa a criar esquemas mentais do processo de demissão tentando validar uma contraditória "ontologia da demissão", em que qualquer profissional que dominasse essa ontologia poderia ser capaz de demitir de qualquer lugar utilizando a tecnologia.

O choque na cultura organizacional da empresa é evidenciado quando Natalie é convidada pelo staff superior a realizar a primeira demissão virtual e verifica que, conceitualmente, a prática era diferente.

A retórica utilizada pela empresa de Ryan durante o processo demissional inclui a narrativa de que, em sua cultura organizacional, a organização está voltada 
para a motivação, acreditando que a demissão não é o fim da vida, e oferece um pacote com alguns benefícios aos então "selecionados". Essa abordagem de novo início pode ser entendida como um dos preceitos de programas de demissão voluntária; esses aspectos foram avaliados como uma alternativa por Carby-Hall (2001).

Do ponto de vista organizacional, o objetivo contraditório de diminuição de custos "a todo custo" destaca-se, porém, sua viabilidade passa por diagnóstico cultural, considerando-se que "deixar de viajar" é uma mudança estrutural profunda, além de a organização não ter pensado se "o bom profissional", que executa sua função viajando, estaria apto a realizar a mesma função "virtualmente" e desconsidera a necessidade de ambientação deste às novas tecnologias, funcionando como um dopping cultural.

Todo esse cenário é causador de caos organizacional perante todos os funcionários que executam as mesmas funções que Ryan, a grande maioria.

Nas demissões realizadas por Ryan, os procedimentos incluem o uso de narrativas de incentivo que tendem a fornecer um "novo olhar de oportunidade" aos recém-demitidos. Essa abordagem aproxima-se da proposta por Eby e Buch (1998), quando o protagonista procura motivar a busca de antigos sonhos até então esquecidos ou deixados de lado e o recomeço em busca de novas oportunidades e perspectivas para suas vidas: “[...] tornar o limbo tolerável para as pessoas demitidas [...] Para transportar pessoas feridas pelo rio do medo até a esperança se tornar vagamente visível. Depois os jogamos na água e os fazemos nadar." (UP IN THE AIR, 2009).

Já do ponto de vista de Natalie, mais tecnicista, imediatista e menos preocupada com as implicações que a solução computacional poderia causar nas relações éticas e interpessoais, as demissões presenciais eram consideradas tarefas desconfortantes, e todo o processo poderia ser esquematizado e realizado virtualmente. Esse posicionamento de Natalie se alinha com a vontade de muitos gestores de fazer uso de soluções já prontas ou, como constatado no estudo de Goodman et al. (1998), a partir da adoção de procedimentos formais escritos, concluindo em seu estudo que os gestores tendem a defender seu uso e apontar benefícios positivos.

Um ponto alto da ontologia da demissão ocorre quando Natalie demite uma das colaboradoras que encara o fato na perspectiva de morte e comete suicídio. Agindo de forma fria e não questionando o ocorrido: "Vou ser demitida, certo? [...] "Não precisa aliviar. Conheço o procedimento. [...] O que me oferecem? [...] Há 
uma bela ponte perto da minha casa. Eu vou pular de cima dela." Colaboradora demitida (UP IN THE AIR, 2009).

O encerramento da discussão passa a ocorrer quando Natalie, ao ser informada que uma das pessoas que ela havia demitido cometera suicídio, jogando-se de uma ponte em sua cidade, demonstra falta de estrutura emocional para continuar em um projeto desse tipo e pede demissão via mensagem de celular.

A discussão relevante aqui não é permeada pela aplicação de tecnologia como fator de redução de custos, mas, sim, pelos fatores humanos e dimensão comportamental, pelo fato de a empresa de outplacement, especialista em desligamentos funcionais e recolocação profissional, ser incapaz de realizar a avaliação do impacto comportamental nos demitidos sob essa nova forma de trabalhar. Esse exemplo corrobora o posicionamento de Freyens e Oslington (2013) em relação às dificuldades que esse processo demissional representa dentro das organizações. As dificuldades que causa, suas consequências e os cuidados que devem ser tomados são ainda descritos por Eby e Buch (1998).

As teorias organizacionais têm explicitado que a aceitação de uma ideia nova exige determinado espaço temporal (KAUFMAN, 1971; KATZ; KAHN, 1978), e o indivíduo tende a rejeitar as mudanças no primeiro momento se não tiver concordado com elas. As mudanças que impactuam na cultura organizacional devem ser melhor analisadas e mais estruturalmente trabalhadas dentro do cenário empresarial, como defendem Freyens e Oslington (2013).

No filme, ao final de todo esse processo de transição, com o pedido de demissão de Natalie, a política de demissão virtual foi temporariamente suspensa e os agentes voltaram a "voar" para realizar seu trabalho.

$\mathrm{Na}$ vida real, situações como essa, além de efetivamente acontecerem, podem deixar marcas profundas na cultura das organizações muito difíceis de cicatrizar e podem expor ao ambiente externo fragilidades e deficiências culturais, além de comprometer seriamente a vida das pessoas.

\section{CONCLUSÃO}

O objetivo principal neste estudo foi realizar uma discussão crítica dos aspectos relativos à aplicação de soluções instantâneas e de forma padronizada na empresa para a solução de conflitos organizacionais. Para tal, a estratégia adotada foi realizar uma interpretação do contexto de relações organizacionais retratado no 
filme $U p$ in the air, a partir da perspectiva direcionada às formas convencionais e contraditórias de realizar o processo demissional. Essa abordagem foi perseguida durante a construção do texto.

As metodologias utilizadas neste trabalho permitiram o uso de um mapa conceitual para demonstração dos conceitos e relacionamentos que foram utilizados na forma de palavras-chave, direcionando a delimitação teórica de análise. As palavras-chave representaram os principais conceitos identificados na relação entre filme e literatura e suas relações com as habilidades esperadas em cada dimensão analisada. Estas puderam direcionar a criação do modelo conceitual da revisão de literatura e direcionar a elaboração do protocolo de pesquisa utilizado para a revisão sistemática da literatura. Dessa forma, todo o critério metodológico, aqui, culminou no protocolo de pesquisa constante no Apêndice B deste estudo e permite a outros pesquisadores replicarem a pesquisa com base nos critérios de busca aplicados na base de dados referencial da Scopus.

As diferentes narrativas do ponto de vista organizacional, dos agentes de demissão, e da perspectiva de solução tecnológica foram confrontadas e buscouse justificar "o final da história” com o que poderia ocorrer do ponto de vista da aplicação adequada da teoria do conhecimento nas organizações. Essas discussões foram fortemente discutidas na seção 4.1, a qual buscou confrontar as formas convencionais, as formas contraditórias e os diferentes contextos de demissão com a abordagem ao filme.

Na análise do filme, a intenção de alteração imediata de valores organizacionais sem haver tempo para avaliar os impactos gerou um clima organizacional instável e acabou por refletir na alteração comportamental dos profissionais demitidos. Não se conseguiu associar as teorias de gestão com as aplicações identificadas no filme, permanecendo uma lacuna que não explicou, na prática das organizações em tela, como ocorre a gestão responsável com políticas e sistemas de incentivo à produtividade. A tentativa de padronizar procedimentos e reações organizacionais acabou por engessar a subjetividade das relações sociais e por alienar as relações individuais, conforme retratado no filme.

Percebeu-se que o processo de demissão é um complicador da atividade empresarial, conforme Kellner, Mcdonald e Waterhouse (2011), com fortes efeitos da legislação (PILAR; MIGUEL, 2007; FREYENS; OSLINGTON, 2013). Isso ocorre em diversos contextos e sofre impacto de diferentes variáveis e motivações, não somente visando à redução de custos (KELLNER; MCDONALD; WATERHOUSE, 2011). As inovações tecnológicas, apesar de bem vistas pelos 
gestores (KUETTNER; DIEHL; SCHUBERT, 2013), assim como a implementação de um rigor mais formalizado (GOODMAN et al., 1998), não foram consideradas, pela abordagem da realidade empresarial trazida no filme, uma boa solução nem adequadas para a realidade da organização. Como visto nos estudos de Eby e Buch (1998), é importante adotar medidas, como gerenciar o processo de demissão, dentro de limites éticos: aviso prévio da perda de emprego, comunicação aberta e serviços de apoio institucionalizados.

Um dos contributos deste trabalho reside na elaboração do modelo conceitual da revisão de literatura, apresentado na seção 3 como um fator de orientação dos achados do filme e como norteador da relação teórica e das práticas identificadas no filme. Destacou-se o protocolo de pesquisa utilizado na base de dados da Scopus para a pré-seleção dos artigos usados na revisão de literatura.

Não foram esgotadas as formas de abordagem apresentadas no filme, tampouco era esse o objetivo neste trabalho, mas, do ponto de vista da abordagem proposta, buscou-se a difícil tarefa de associar a abordagem à área de administração e contabilidade, utilizando-se, para isso, a forma de tratar a demissão com base nos preceitos legais e associá-la às práticas em vigor.

Como principal lição aprendida nesse contexto, pode-se destacar que a aplicação de soluções tecnológicas, instantâneas e padronizadas, dentro do ambiente organizacional, pode assumir a forma de geradora de conflito e caos sistêmico, caso não se aplique adequadamente a teoria do conhecimento em gestão para evitar efeitos indesejados, como, por exemplo, o dopping cultural percebido no filme.

Como perspectiva para trabalhos futuros, sugere-se analisar de que modo os processos de demissão voluntária ou com a utilização de uma ferramenta tecnológica são adotados na prática pelas empresas.

\section{REFERÊNCIAS}

CAÑAS, A. J. et al. Herramientas para construir y compartir modelos de conocimiento basados en mapas conceptuales. Revista de Informática Educativa, v. 13, n. 2, p. 145-158, 2000.

CARBY-HALL, J. A voluntary alternative route for unfair dismissal claims: Arbitration. Managerial Law, v. 43, i. 5, p. 1-29, 2001.

DENZIN, N. K.; LINCOLN, Y. S. The Sage handbook of qualitative research. 4th. ed. United States: Sage, 2005. 
EBY, L. T.; BUCH, K. The impact of adopting an ethical approach to employee dismissal during corporate restructuring. Journal of Business Ethics, v. 17, i. 12, p. 1253-1264, 1998.

FREYENS, B. P.; OSLINGTON, P. A First Look at Incidence and Outcomes of Unfair Dismissal Claims under Fair Work, WorkChoices and the Workplace Relations Act. Australian Journal of Labour Economics, v. 16, i. 2, p. 295-306, 2013.

GOODMAN, J. et al. Unfair dismissal cases, disciplinary procedures, recruitment methods and management style Case study evidence from three industrial sectors. Employee Relations, v. 20, i. 6, p. 536-549, 1998.

GRAY, B.; BOUGON, M. G.; DONNELLON, A. Organizations as constructions and destructions of meaning. Journal of management, v. 11, i. 2, p. 83-98, 1985.

GRUND, C. Severance payments for dismissed employees in Germany.

European Journal of Law and Economics, v. 22, i. 1, p. 49, 2006.

HAGEMANS, M. G.; VAN DER MEIJ, H.; DE JONG, T. The effects of a concept map-based support tool on simulation-based inquiry learning. Journal of Educational Psychology American Psychological Association, v. 105, i. 1, p. 1-24, 2013.

HARAN, U. A Person-Organization Discontinuity in Contract Perception: Why Corporations Can Get Away with Breaking Contracts But Individuals Cannot. Management Science, v. 59, i. 12, p. 2837-2853, 2013.

HILLIARD, I. Responsible Management, Incentive Systems, and Productivity. Journal of Business Ethics, v. 118, i. 2, p. 365-377, 2013.

KATZ, D.; KAHN, R. Psicologia Social das Organizações. São Paulo: Atlas, 1978.

KAUFMAN, H. The Limits of Organizational Change. New Jersey: University of Alabama Press, 1971.

KELLNER, A.; MCDONALD, P.; WATERHOUSE, J. Sacked! An investigation of young workers dismissal. Journal of Management and Organization, v. 17, i. 2, p. 226-244, 2011.

KUETTNER, T.; DIEHL, R.; SCHUBERT, P. Change factors in Enterprise 2.0 initiatives: Can we learn from ERP? Electronic Markets, v. 23, i. 4, p. 329-340, 2013. 
MARTIN-ROJAS, R.; GARCIA-MORALES, V. J.; BOLIVAR-RAMOS, M. $\mathrm{T}$. Influence of technological support, skills and competencies, and learning on corporate entrepreneurship in European technology firms. Technovation, v. 33, i. 12, p. 417-430, 2013.

MILLER, M. V; ROBINSON, C. Managing the Disappointment of Job Termination: Outplacement as a Cooling-Out Device. The Journal of Applied Behavioral Science, v. 40, i. 1, p. 49-65, 2004.

MOON, B. et al. Applied concept mapping: Capturing, analyzing, and organizing knowledge. Boca Ratom, Flórida: CRC Press Taylor \& Francis Group, 2011.

MORIN, W. J.; YORKS, L. Dismissal: there is no easy way but there is a better way. New York: Drake Beam Morin, 1990.

NG, T. W. H.; FELDMAN, D. C. Does longer job tenure help or hinder job performance? Journal of Vocational Behavior, v. 83, i. 3, p. 305-314, 2013 a.

NG, T. W. H.; FELDMAN, D. C. How do within-person changes due to aging affect job performance? Journal of Vocational Behavior, v. 83, i. 3, p. 500-513, 2013b.

PILAR, G. M.; MIGUEL, Á. M. The strategic use of dismissal legislation: an empirical analysis using Spanish data. European Journal of Law and Economics, v. 23, i. 2, p. 151-167, 2007.

SAUR-AMARAL, I. Towards a Methodology for Literature Reviews in Social Sciences. In: INVESTIGAÇÃO E INTERVENÇÃO EM RECURSOS HUMANOS 2011 - GESTÃO PARA A CIDADANIA, 2011, Porto. Anais... Porto: Escola Superior de Estudos Industriais e de Gestão do Instituto Politécnico do Porto, 2011.

SOUTHEY, K. Forward with Unfair Dismissal Claims. Labour \& Industry, v. 19, i. $1 / 2$, p. $25-48,2008$.

STIEBER, J.; BLOCK, R. N.; KRUEGER, A. B. Comment on Alan B. Krueger, "The Evolution of Unjust-Dismissal Legislation in the United States"; Reply. Industrial \& Labor Relations Review, v. 45, i. 4, p. 792, 1992.

TRANFIELD, D.; DENYER, D.; SMART, P. Towards a methodology for developing evidence-informed management knowledge by means of systematic review. British journal of management, v. 14, i. 3, p. 207-222, 2003. 
TRANFIELD, D.; MOUCHEL, D. D. Developing an evidence-based approach to management knowledge using systematic review. Advanced Management Research Centre, Stockholm: Cranfield School of Management, 2002 .

UP in the air. Direção de Jason Reitman. Produção de Jeffrey Clifford, Daniel Dubiecki, Ivan Reitman, Jason Reitman. United States of America: Paramount Pictures, Cold Spring Pictures, The Montecito Picture Company, Right of Way Films, DreamWorks Pictures, 2009. Filme (104min).

\section{COMO CITAR ESTE ARTIGO:}

PEREIRA, Cleber Augusto; PEREIRA, Neimar Sousa Pino; MONTEIRO, Renato Pereira. Soluções instantâneas e padronizadas utilizando a gestão do conhecimento: uma abordagem quanto às formas de demissão. RACE, Revista de Administração, Contabilidade e Economia, Joaçaba, Ed. Unoesc, v. 14, n. 3, p. 1269-1296, set./dez. 2015. Disponível em: < http://editora.unoesc.edu.br/ index.php/race >. Acesso em: dia/mês/ano.

Pereira, C. A., Pereira, N. S. P., \& Monteiro, R. P. (2015). Soluções instantâneas e padronizadas utilizando a gestão do conhecimento: uma abordagem quanto às formas de demissão. RACE, Revista de Administração, Contabilidade e Economia, 14(3), p. 1269-1296. Recuperado em: dia/mês/ano, de http://editora.unoesc.edu.br/index. php/race 


\section{APÊNDICE A}

\section{IDENTIFICAÇÃO DO FILME UTILIZADO COMO BASE PARA ESTE ARTIGO}

Nome original do filme: $U p$ in the air

Nome utilizado na versão brasileira: Amor sem escalas

FICHA TÉCNICA

Diretor: Jason Reitman.

Ano de lançamento: 2009.

Elenco: Jason Bateman, George Clooney, Anna Kendrick, Vera Farmiga, Melanie Lynskey, Danny McBride, Chris Lowell, Tamala Jones.

Produção: Jeffrey Clifford, Daniel Dubiecki, Ivan Reitman, Jason Reitman.

Roteiro: Jason Reitman, Sheldon Turner.

Fotografia: Eric Steelberg.

Trilha sonora: Rolfe Kent.

Duração: 104 min.

País: EUA.

Gênero: Comédia Dramática.

Estúdio: Paramount Pictures / Cold Spring Pictures / The Montecito Picture Company / Right of Way Films / DreamWorks Pictures. 


\section{APÊNDICE B: PROTOCOLO DE PESQUISA}

\begin{tabular}{|c|c|}
\hline Conteúdo & oo \\
\hline $\begin{array}{r}\text { Obj } \\
\text { pe }\end{array}$ & $\begin{array}{l}\text { Pretende-se realizar uma pesquisa de revisão de literatura sobre as palavras-chave } \\
\text { previamente definidas na proposta de metodologia de análise de filme constante no item } 2.1 \\
\text { deste estudo. } \\
\text { O objetivo é construir um quadro teórico de congruência entre trabalhos semelhantes. } \\
\text { Será composto por artigos de qualidade acadêmica, de fontes de publicação relevantes e } \\
\text { publicados em veículos de comunicação de reconhecida qualidade internacional. Os artigos } \\
\text { devem apresentar estudos associados à teoria organizacional. }\end{array}$ \\
\hline $\begin{array}{l}\text { Equações de } \\
\text { pesquisa a } \\
\text { experimentar }\end{array}$ & $\begin{array}{l}\text { As palavras-chave que formam a equação de pesquisa são: dismiss, “organizational theory", } \\
\text { "dismiss law", "outplacement", "occupational contexts", "ethical approach" e "job } \\
\text { termination". }\end{array}$ \\
\hline $\begin{array}{r}\hat{A} \mathbf{n} \\
\text { pe }\end{array}$ & $\begin{array}{l}\text { Delimitação do espaço de pesquisa: } \\
\text { A base de dados escolhida para a busca foi a Scopus da Elsevier B.V. } \\
\text { - Será feita uma avaliação das publicações e pretende-se usar apenas as fontes de } \\
\text { publicação que possuam publicações na área de Business, Management e Accounting. } \\
\text { - Período de pesquisa: resultados procurados incluem-se em um período (inclusive), entre } \\
2011 \text { e } 2013 \text {. } \\
\text { - Será realizada a leitura de todos os títulos e resumos/abstracts previamente selecionados } \\
\text { - } \text { - Somente serão incluídos os artigos de journals com reputação relevante. }\end{array}$ \\
\hline $\begin{array}{c}\text { Crit } \\
\text { in }\end{array}$ & $\begin{array}{l}\text { - Fontes de Publicação que possuam no título: dismiss, "organizational theory", "dismiss } \\
\text { law", “outplacement", "occupational contexts", "ethical approach" e "job termination". } \\
\text { - Publicações da área de Business, Management e Accounting; } \\
\text { - Publicações encontradas entre } 2010 \text { a 2013, preferencialmente já citadas; }\end{array}$ \\
\hline $\begin{array}{r}\text { Crit } \\
\text { exc }\end{array}$ & $\begin{array}{l}\text { - Publicações fora da área Business, Management e Accounting; } \\
\text { - Publicações fora do período de } 2010 \text { a 2013; } \\
\text { - Publicações diferentes de "artigos completos". }\end{array}$ \\
\hline $\begin{array}{l}\text { Critérios de } \\
\text { qualidade e } \\
\text { validade } \\
\text { metodológica }\end{array}$ & $\begin{array}{l}\text { - Registrar todos os passos realizados durante a pesquisa e justificação das decisões } \\
\text { tomadas (transparência); } \\
\text { - Será feita a leitura de todos os títulos e seus abstracts para confirmação se realmente a } \\
\text { publicação analisada está dentro da vertente desejada. }\end{array}$ \\
\hline
\end{tabular}




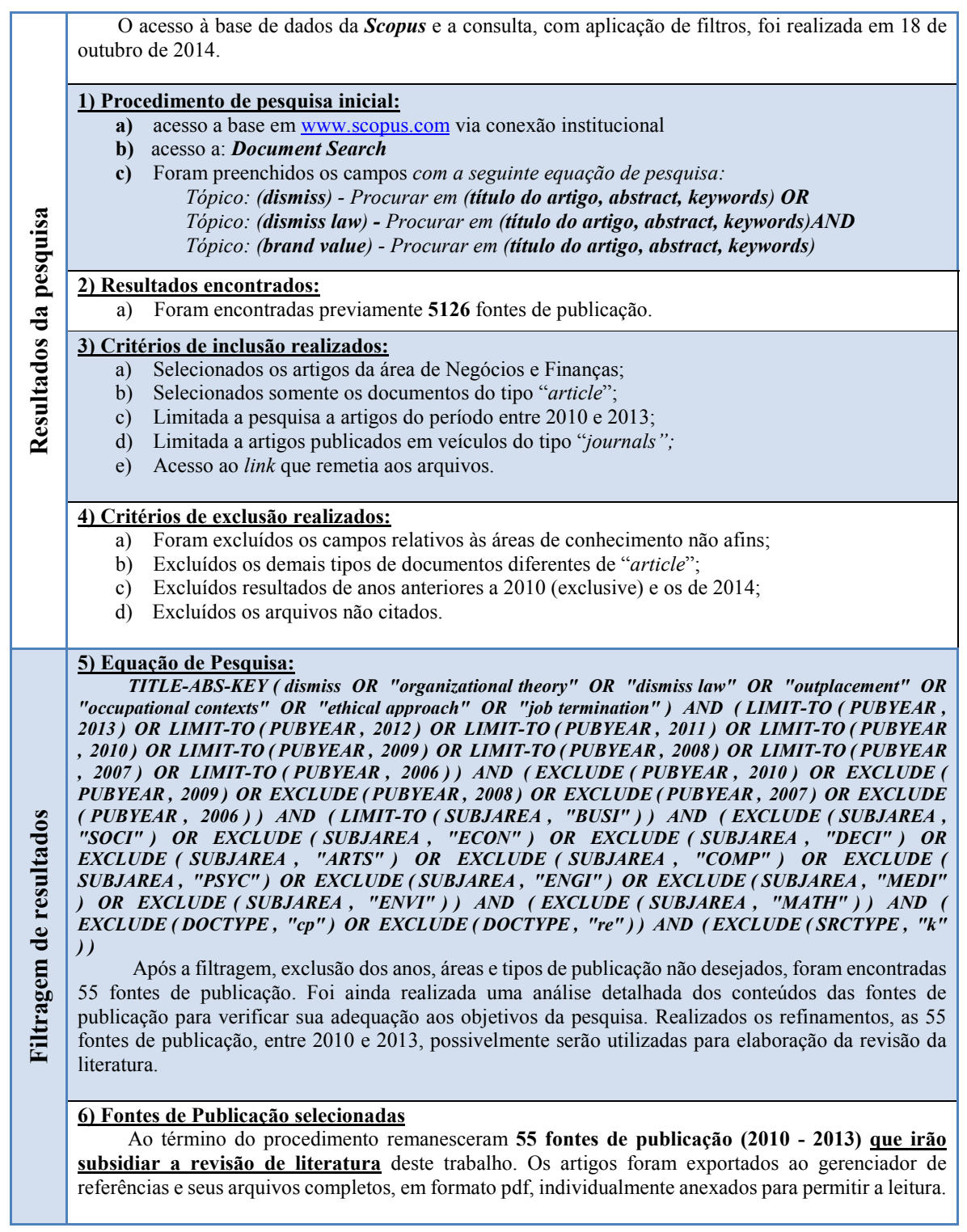

